\title{
PROPAGATION OF STRESS WAVES IN THIN ORTHOTROPIC PLATES
}

\author{
Frantisek Klimenda, Josef Soukup, Blanka Skocilasova \\ J. E. Purkyne University in Usti nad Labem, Czech Republic \\ frantisek.klimenda@ujep.cz
}

\begin{abstract}
The article deals with the issue of longitudinal and transverse wave propagation in the body of the thin viscoelastic orthotropic plate of Glass-Epoxy composite material. The plate has dimensions $0.1 \times 0.1 \times 0.0005$ $\mathrm{m}$. This plate was circumferentially fixed and loaded by impact force $1 \mathrm{~N}$ in the centre of the plate (impact centre). The impact load was induced by the steel thin rod with spherical contact end. The radius of the rod $c$ is $0.0025 \mathrm{~m}$. For determination of the wave propagation of the plate the Kirchhoff model orthotropic plate, which is based on the Voight-Kelvin model, was used. The material properties of Glass-Epoxy are taken from literature material lists. These quantities are density, Poisson number, tensile modulus and shear modulus for $x, y$, and $z$ directions. The calculation of displacements and velocities in the axes direction $(x, y, z)$ was solved in MATLAB programme. The maximum calculation time reached $2 \times 10^{-5} \mathrm{~s}$, the time step of the calculation was applied up to $2 \times 10^{-7} \mathrm{~s}$. The waves are propagated from the impact centre in all directions. The wave propagation in $x, y, z$ direction was determined at three points (B1, B2, B3 - position is presented in Figure 2) at a distance of $10 \mathrm{~mm}$ from the impact centre. The results, i.e. the displacements and the velocities at each observed point, are shown in Figures 3 to Figures 8 . The coordinates of the points, in which the displacements and velocities were determined, are B1 $[0.01 ; 0.00 ; 0.00], \mathrm{B} 2[0.01 ; 0.01 ; 0.00]$ and B3 $[0.00 ; 0.01 ; 0.00]$. The results show that the velocity of the longitudinal wave propagation (i.e. in the $x$ and $y$ direction) is approximately 1.5 times greater than the velocity of a transverse wave dissemination (i.e. in the $z$ direction). This result is in accordance with the wave theory.
\end{abstract}

Keywords: orthotropy, vibration, velocity, thin plate, wave propagation.

\section{Introduction}

Wave propagation problems investigated in the bodies, especially in plates and beams, have been in the scope of engineers and scientist since the end of the 18th century. At the beginning of the 19th century, Napoleon declared a financial reward to enhance the progress of this problem solution, which was one of the most national importances. This issue has not yet been satisfactorily resolved. A number of studies and monographs have been published [1-3], plate vibrations are a permanent topic, different tasks are dealt with [4], different effects are being analyzed, and different methods of solution are used [5-8]. The most sophisticated solution is the non-stationary oscillation of elastic isotropic plates [9]; the solution of orthotropic plates is limited to several studies [10-12]. The Faculty of Mechanical Engineering has been engaged in long-term research, dealing mainly with solutions of non-stationary character [13-15]. During that time, the Department of Machines and Mechanics established new approaches and solutions and worked on a comprehensive theory of wave propagation in thin plates.

There are a number of material and geometric models of solutions. The basic material model is the Hook's model, from geometric models it is the Kirchhoff's model, which defines a thin plate model considering only the vertical shifting of the board and its corresponding inertial effects. The Rayleigh's model arranges this basic model by incorporation of the effect of cross-section rotation and corresponding inertial effect. The Flügge's model considers the effect of shear on the resulting vertical displacement, the Timoshenko-Mindlin's model considers both influences - influence of the turning of the cross section and the effect of the shear.

\section{Materials and Methods}

In this article we deal with the propagation of shock waves in a thin plate for which the Kirchhoff's geometric model was chosen. The displacements and velocities of wave propagation are solved in the direction $x, y$ and $z$. Calculation in MATLAB is based on simple assumptions that significantly affect the results

- plate geometry - the size and nature of its strain, layout, and the character of the excited load

- rheological properties of the plate's material 
- simplified assumptions within the framework of the used methods of solution - the assumption of small deformations, the linearity of the relationship, and thus the superposition principle, neglect of the shear effect, etc.

For the computational model of the plate according to Kirchhoff's theory for the orthotropic plate, it is possible to derive the strain of the plate as a function of displacements in the direction of axes $-x$, $y, z$, resp. $u, v, w$. The solution is presented for a specific case, where the bar impacts perpendicularly to the thin elastic plate, based on the condition of equality of the contact point A shifts in both bodies in the direction $z$ (Fig. 1).

$$
\begin{gathered}
w_{\mathrm{A} 1}=w_{\mathrm{A} 2} \\
w_{K \mathrm{~A} 1}+w_{D \mathrm{~A} 1}=w_{T 2}-w_{K \mathrm{~A} 2}-w_{D \mathrm{~A} 2},
\end{gathered}
$$

where $\quad w_{\mathrm{A} 1}-$ displacement of the touch pad A of the plate, $\mathrm{m}$;

$w_{\mathrm{A} 2}-$ displacement of the touch pad A of the rod, $\mathrm{m}$;

$w_{K A 1}$ - oscillating displacement of the projection of point $\mathrm{A}$ to lower face in the $z$ direction, $\mathrm{m}$;

$w_{D A 1}$ - displacement of the touch deformation of the upper face, m;

$w_{\mathrm{T} 2}$ - displacement of the falling rod as a rigid body, m;

$w_{\mathrm{K} 2}-$ displacement of the flexible loose rod, $\mathrm{m}$;

$w_{\mathrm{D} 2}-$ displacement of the rod deformation, $\mathrm{m}$.

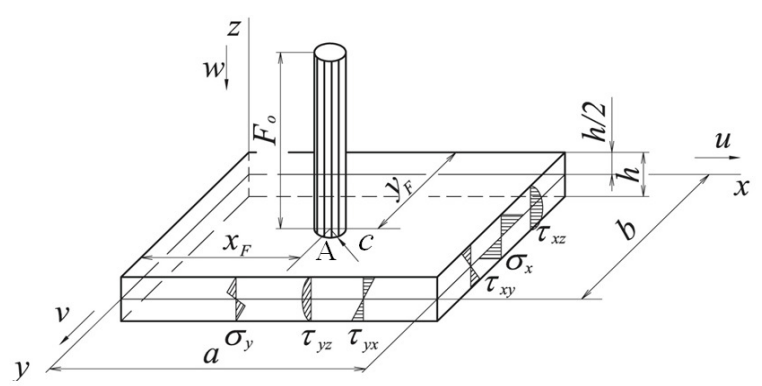

Fig. 1. Plate model: $a, b, h$-plate dimensions; $c$-impact radius; $F(t)$-impact force;

$x_{F}, y_{F}-$ force coordinates; $\sigma_{\mathrm{x}}, \sigma_{\mathrm{y}}-$ bending stresses; $\tau_{\mathrm{yx}}, \tau_{\mathrm{xy}}, \tau_{\mathrm{xz}}, \tau_{\mathrm{yz}}-$ shear stresses

Vertical displacement for the Kirchhoff's model of orthotropic thin plate $w(x, y, t)$

$$
\begin{array}{ccc}
w(x, y, t) & =\frac{16}{a b c} \frac{F_{0}}{\rho h} \sum_{m=1}^{\infty} \sum_{n=1}^{\infty} \frac{J_{1}\left(\gamma_{m n} c\right)}{\gamma_{m n}} \frac{\sin \left(\alpha_{n} x_{F}\right) \sin \left(\beta_{m} y_{F}\right)}{\omega_{m n}^{2}} \sin \left(\alpha_{n} x\right) \sin \left(\beta_{m} y\right) \sin ^{2}\left(\frac{\omega_{m n}}{2} t\right) \\
\omega_{m n}^{2}=\frac{1}{\rho h}\left(D_{x} \alpha_{n}^{4}+2 D_{x y} \alpha_{n}^{2} \beta_{m}^{2}+D_{y} \beta_{m}^{4}\right) & \beta_{m}=m \frac{\pi}{b} \\
\gamma_{m n}=\sqrt{\alpha_{n}^{2}+\beta_{m}^{2}} & \alpha_{n}=n \frac{\pi}{a} & D_{x y}=G_{x y} \frac{h^{3}}{12}
\end{array}
$$

Angles of rotation tangent $\varphi_{x}$ and $\varphi_{y}$ (Fig. 2)

$$
\begin{aligned}
\varphi_{x}= & \frac{\partial w}{\partial x}=\frac{16}{a b c} \frac{F_{0}}{\rho h} \sum_{m=1}^{\infty} \sum_{n=1}^{\infty} \frac{J_{1}\left(\gamma_{m n} c\right)}{\gamma_{m n}} \frac{\alpha_{n}}{\omega_{m n}^{2}} \sin \left(\alpha_{n} x_{F}\right) \sin \left(\beta_{m} y_{F}\right) \cos \left(\alpha_{n} x\right) \sin \left(\beta_{m} y\right) . \\
& \cdot \sin ^{2}\left(\frac{\omega_{m n}}{2} t\right)
\end{aligned}
$$




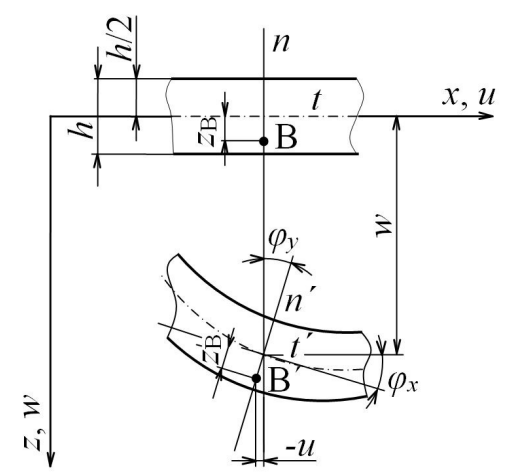

Fig. 2. Rotation of plate element: $n, n^{\prime}-$ normal; $t, t^{\prime}-$ tangents; $u, w$-displacement in $x$ and $y$ direction $x$ and $y ; \varphi_{\mathrm{x}}, \varphi_{\mathrm{y}}$ - angles of cross-sectional rotation in $x$ and $y$ direction; $\mathrm{B}, \mathrm{B}^{\prime}-$ control point; $z_{\mathrm{B}}, z_{\mathrm{B}}{ }^{\prime}-$ distance of point $\mathrm{B} ; h-$ thickness of plate

Angles of rotation tangent $\varphi_{x}$ and $\varphi_{y}$ (Fig. 2)

$$
\begin{aligned}
\varphi_{y}= & \frac{\partial w}{\partial y}=\frac{16}{a b c} \frac{F_{0}}{\rho h} \sum_{m=1 n=1}^{\infty} \sum_{1}^{\infty} \frac{J_{1}\left(\gamma_{m n} c\right)}{\gamma_{m n}} \frac{\beta_{m}}{\omega_{m n}^{2}} \sin \left(\alpha_{n} x_{F}\right) \sin \left(\beta_{m} y_{F}\right) \sin \left(\alpha_{n} x\right) \cos \left(\beta_{m} y\right) . \\
& \cdot \sin ^{2}\left(\frac{\omega_{m n}}{2} t\right)
\end{aligned}
$$

Displacement $u$ and $v$ in $x$ and $y$ direction

$$
u=-z \varphi_{x} \quad v=-z \varphi_{y},
$$

Velocity of wave $\dot{u}, \dot{v}, \dot{w}$

$$
\dot{u}=\frac{\partial u}{\partial t} \quad \dot{v}=\frac{\partial v}{\partial t} \quad \dot{w}=\frac{\partial w}{\partial t},
$$

where $a, b, h$-plate dimensions, $\mathrm{m}$;

$c$ - impact radius, $\mathrm{m}$;

$\rho$ - density of plate, $\mathrm{kg} \cdot \mathrm{m}^{-3}$

$F_{0}$ - impact force, $\mathrm{N}$;

$J_{1}\left(\gamma_{m n} c\right)$ - Bessel's function of the first kind, the first order for the $\gamma_{m n} c$ argument, -;

$\alpha, \beta$ - constants, $\mathrm{m}^{-1}$;

$m, n$ - matrix elements, -;

$x_{F}, y_{F}$ - coordinate of the circular load, $\mathrm{m}$;

$x, y, z$-coordinates of the control point, $\mathrm{m}$;

$\omega_{m n}-$ own frequency, $\mathrm{Hz}$;

$t$ - time, $\mathrm{s}$;

$D_{x}, D_{y}, D_{y x}-$ plate stiffness in individual direction, $\mathrm{N} \cdot \mathrm{m}$;

$E, G-$ tensile and shear modulus, $\mathrm{Pa}$;

$\mu_{x}, \mu_{y}, \mu_{x y},-$ Poisson number in individual direction.

\section{Results and Discussion}

The relations for calculating the displacements and velocities were numerically solved in MATLAB. The viscoelastic thin orthotropic plate "Glass-Epoxy" was solved, the material properties are given in Table 1. The plate has got a dimension of $0.1 \times 0.1 \times 0.0005 \mathrm{~m}$ (Fig. 3). The impact load was caused by rod with diameter $2 c=0.005 \mathrm{~m}$. The value of the impact load was $F_{0}=1 \mathrm{~N}$. The force position was in the centre of the plate. The plate was fixed around a perimeter. The magnitude of the displacements and velocities induced by the propagating wave in the thin plate was determined in points B1, B2, B3 - see Table 2.

In Fig. 4, 5 and 6 the graphs of displacement $u, v, w$ for the individual control points (B1 to B3) are shown. In Fig. 7, 8 and 9 the graphs of velocity " $u, v, w$ " for the individual control points (B1 to B3) are shown. 
Material properties of Glass-Epoxy

Table 1

\begin{tabular}{|c|c|c|c|}
\hline Name & Des. & Unit & Value \\
\hline \multirow{3}{*}{ Tensile modulus } & $E_{x}$ & $\mathrm{~Pa}$ & $3.86 \times 10^{10}$ \\
\cline { 2 - 4 } & $E_{y}$ & $\mathrm{~Pa}$ & $8.27 \times 10^{9}$ \\
\cline { 2 - 4 } & $E_{z}$ & $\mathrm{~Pa}$ & $8.27 \times 10^{9}$ \\
\hline \multirow{3}{*}{ Modulus of shear elasticity } & $G_{y z}$ & $\mathrm{~Pa}$ & $3.45 \times 10^{9}$ \\
\cline { 2 - 4 } & $G_{x z}$ & $\mathrm{~Pa}$ & $4.14 \times 10^{9}$ \\
\cline { 2 - 4 } & $G_{x y}$ & $\mathrm{~Pa}$ & $4.14 \times 10^{9}$ \\
\hline \multirow{3}{*}{ Poisson's number } & $\mu_{y z}$ & - & 0.2 \\
\cline { 2 - 4 } & $\mu_{z x}$ & - & 0.043 \\
\cline { 2 - 4 } & $\mu_{x y}$ & - & 0.2 \\
\hline Density & $\rho$ & $\mathrm{kg} \cdot \mathrm{m}^{-3}$ & 1800 \\
\hline
\end{tabular}
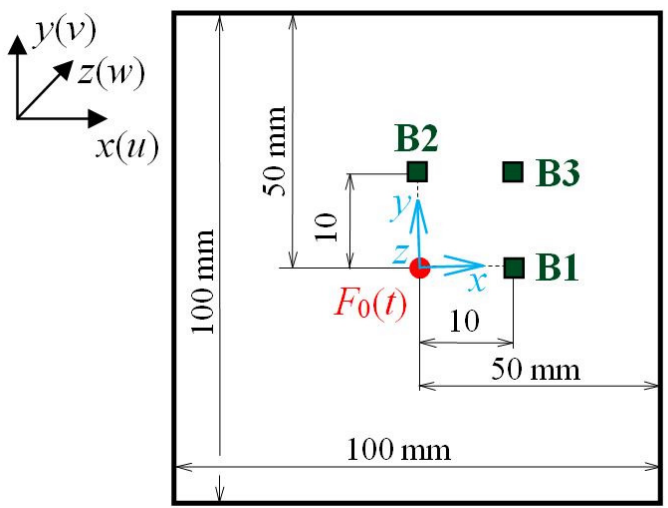

Fig. 3. Plate dimensions and impact center: $F_{0}(t)$ - impact load, B1, B2, B3 - control points
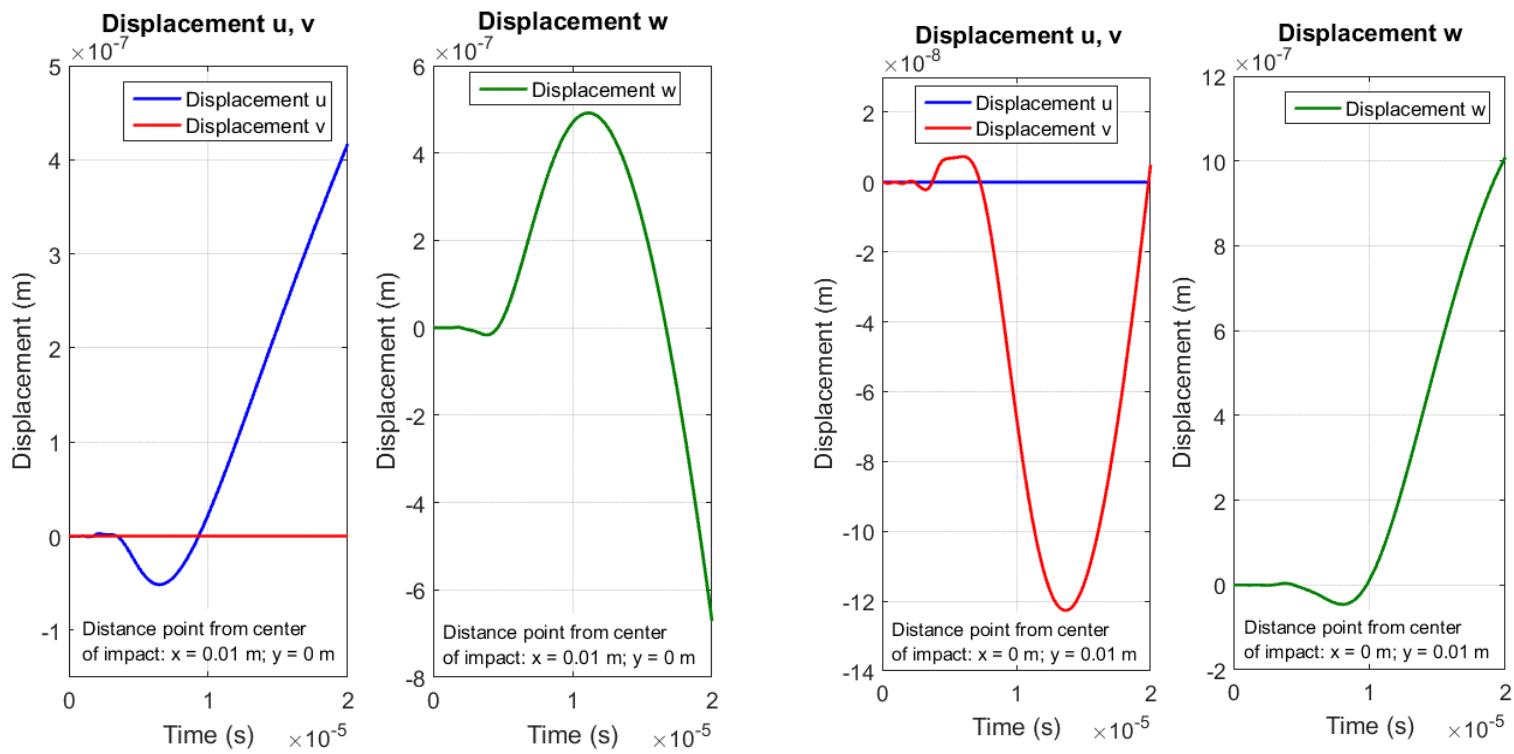

Fig. 4. Displacement " $u, v, w$ " in point B1

Fig. 5. Displacement " $u, v, w$ " in point $\mathrm{B} 2$

By comparing the variations in Fig. 4 with Fig. 6, the variations are different for B1 and B3. This is due to the fact that the material properties are different in the direction of the $x$ and $y$ axes - it is actually an orthotropic material.

The displacement at point B3 shows a relatively equal course in the $x$ and $y$ axis. The amplitude is different, which means that it is an orthotropic material. Point B3 is away from the centre of impact of 
$0.0141 \mathrm{~m}$ (points B1 and B2 $-0.01 \mathrm{~m}$ ). Fig. 4, 5 and 6 show different amplitude (B3 in both directions smaller). This is due to material attenuation (distance is greater than $0.0041 \mathrm{~m}$ ).

Table 2

\section{Control points}

\begin{tabular}{|c|c|c|}
\hline \multirow{2}{*}{$\begin{array}{c}\text { Des. } \\
\text { points }\end{array}$} & \multicolumn{2}{|c|}{ Position of points from the centre of impact } \\
\cline { 2 - 3 } & $x, \mathrm{~m}$ & $y, \mathrm{~m}$ \\
\hline B1 & 0.01 & 0.00 \\
\hline B2 & 0.00 & 0.01 \\
\hline B3 & 0.01 & 0.01 \\
\hline
\end{tabular}
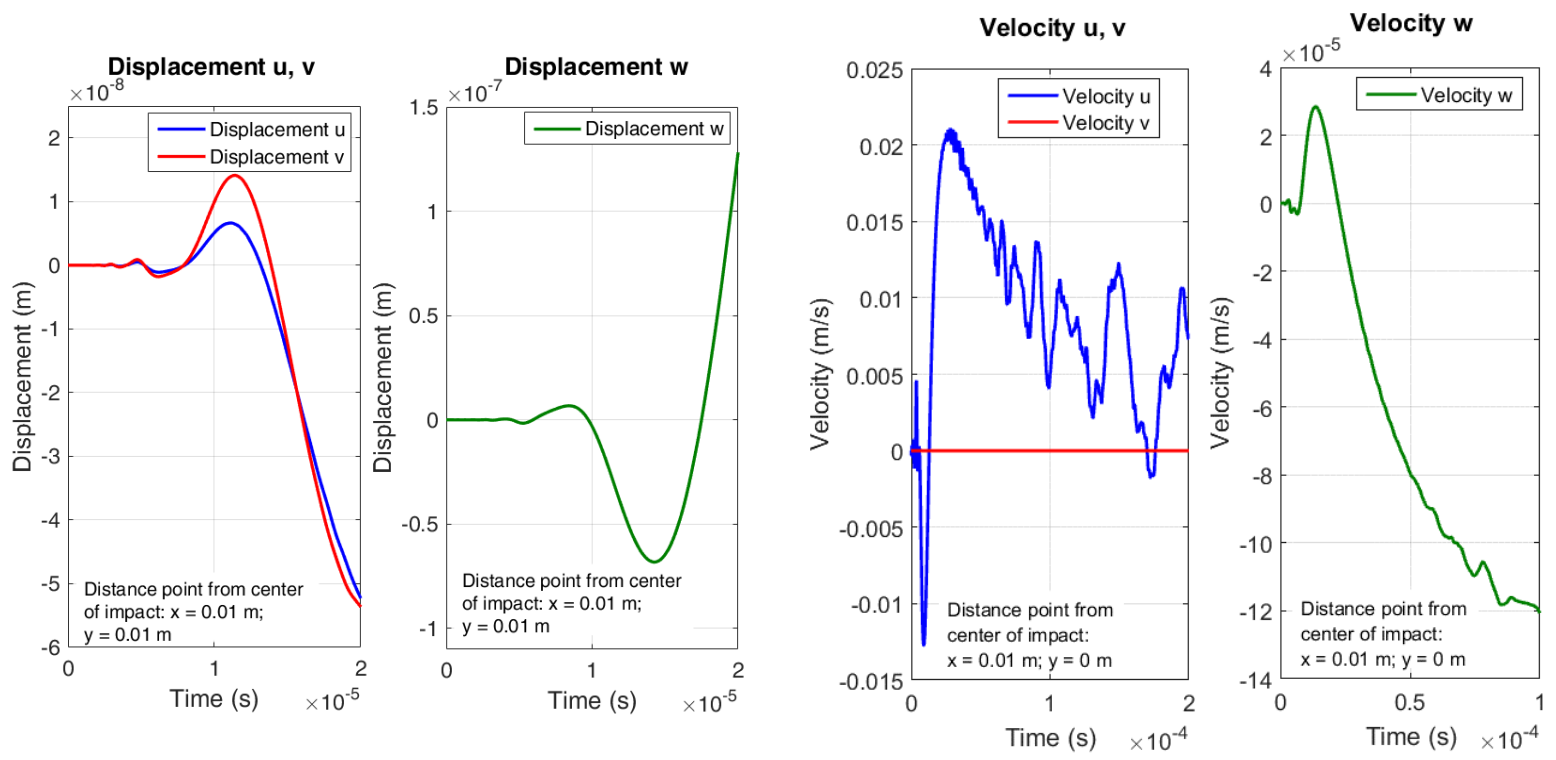

Fig. 6. Displacement " $u, v, w$ " in point $\mathrm{B3}$
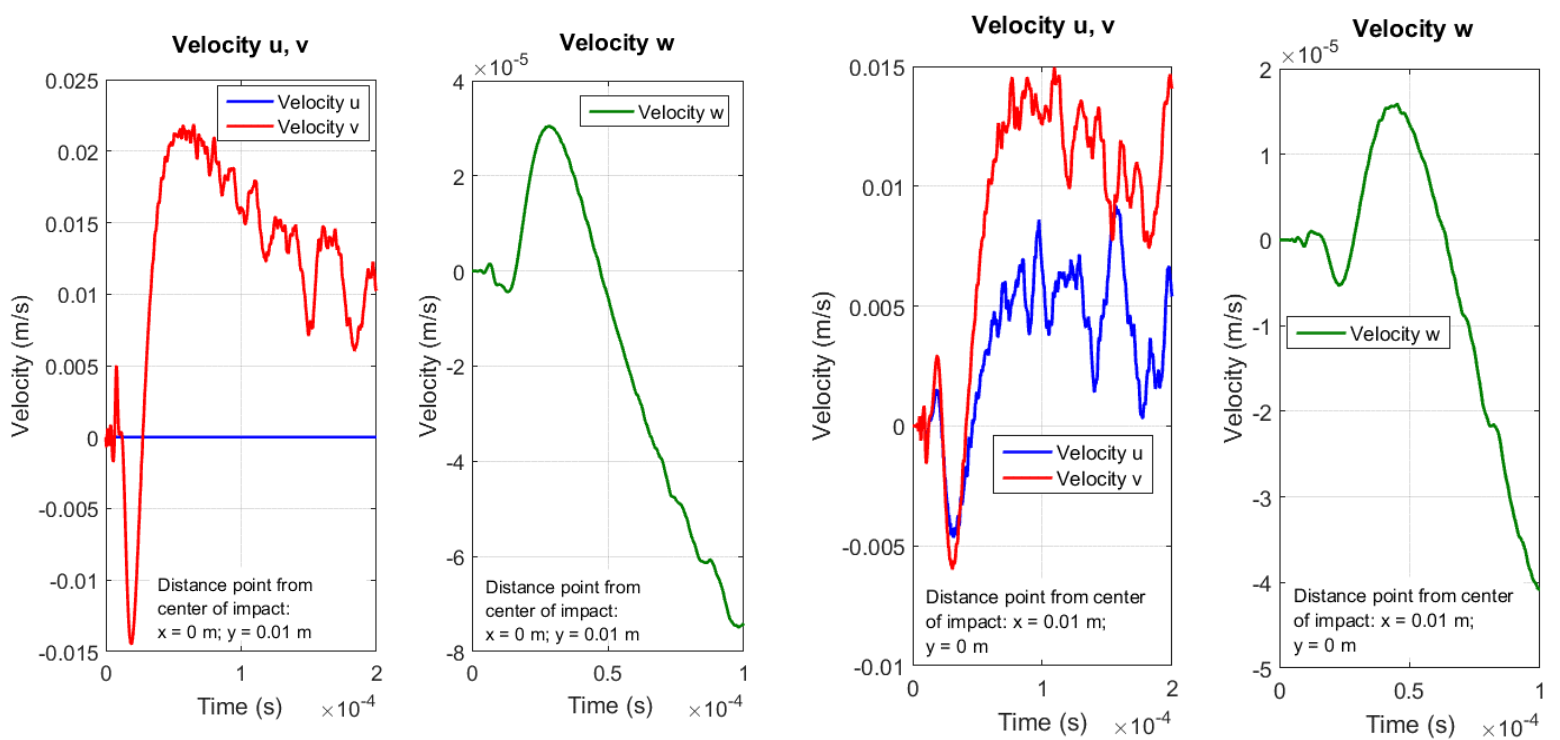

Fig. 8. Velocity " $u, v, \dot{w} w^{*}$ in point $\mathrm{B} 2$

Fig. 9. Velocity " $u, \dot{v}, \dot{w}$ " in point $\mathrm{B} 3$

The amplitudes in the direction $x$ and $y$ (points B1, B2) are different, as well as the times, see Fig. 6,7 and 8 . This is due to material attenuation in the axes - the orthotropic material. At point B3, there 
is a clear displacement of the peaks at the $x$-axis versus $y$-axis (different material properties), as well as the amplitudes are different.

\section{Conclusions}

The oscillation of the orthotropic plate, which had different rheological properties in the $\mathrm{x}$ and $\mathrm{y}$ axes, was solved. $Z$-axis properties are the same at all control points. The difference in these properties $\left(E_{x} \neq E_{y}, G_{y z} \neq G_{x z}\right)$ also manifests itself at different velocities in these axes. The course of deflection in $x$ and $y$ corresponds well to rheological properties. This difference is reflected in the velocity of the wave propagation (time $t$ ) and the amplitude of both displacement and velocity.

The further step of the investigation is to perform the Timoshenko-Mindlin calculation and compare it with the experiment.

\section{Acknowledgements}

The research work is supported by the SGS - UJEP, Czech Republic.

\section{References}

[1] Brepta R., Okrouhlík M., Valeš F. Wave and impact phenomena in solid bodies and methods of its solution, in original: Vlnové a rázové děje $\mathrm{v}$ pevných tělesech a metody jejich řešení. 1. vydání. Praha: Academia, 1985, 172 s.

[2] Babuska I., Li L.: The problem of plate modelling. Theoretical and computional results. Comput. Methods Applied Mech. Engrg. 100, 1992, pp. 249-273.

[3] Darus M.I.Z., Tokhi M. O. Dynamical modelling and simulation of flexible rectangular isotropic plate structure ucing finite difference method, United Kingdom, 2010, 6 p.

[4] Haciyev V.C., Sofiyev A.H., Kuruoglu N. On the free vibration of orthotropic and inhomogeneous with spatial coordinates plates resting on the inhomogeneous viscoelastic foundation, Mechanics and Advanced Materials and Structures, 2018.

[5] Khorshidi K. Elasto-Plastic Response of Impacted Moderatly Thick Rectangular Plates with Different Boundary Conditions, In. Procedia Enginering 10, 2011, pp. 1742-1747.

[6] Hsu M.-H. Vibration Analysis of Isotropic and Orthotropic Plates with Mixed Boundary Conditions, In. Tamkang Journal of Science and Engineering, Vol. 6, No. 4, 2003, pp. 217-226.

[7] Vanam B., Inala R. Static analysis of an isotropic rectangular plate using finite element method (FEM). In. Journal of Mechanical Engineering Research, Vol. 4, 2012, pp. 148-162.

[8] Sobotka Z. Free vibrations of viscoelastic rectangular plates, Acta technica, No. 6, 1978, pp. 678-705.

[9] Sakata T., Hosokawa K. Vibrations of clamped orthotropic rectangular plate, Journal of Sound and Vibration, Vol. 125, 1988, pp. 429-439.

[10] Thai H.T., Kim S.E. Levy-type solution for free vibration analysis of orthotropic plates based on two variable refines plate theory, Applied Mathematical Modelling, Vol. 36, 2012, pp. 3870-3882.

[11] Jayaraman G., Chen P., Snyder V.W, Free vibrations of rectangular orthotropic plates with a pair of parallel edges simply supported, Computers and Structures, Vol. 34, 1990, pp. 203-214.

[12] Hadi G.B., Soheil R. A simple analytical model for free vibration of orthotropic and functionally graded rectangular plates, Alexandria Engineering Journal, in press, 2017.

[13] Soukup J., Zmindak M., Skocilas J., Rychlikova L. Application of Mesh-free Methods in Transient Dynamic Analysis of Orthotropic Plates, Manufacturing technology, Vol. 14, No. 3, 2014, pp. 441-447, ISSN 1213-2489.

[14]Zmindak M., Pelagic Z., Soukup J. Analysis of Fiber Orientation Influence to Dynamic Properties of Composite Structures, Manufacturing technology, Vol. 15, No. 3, 2015, pp. 490-494, ISSN 1213-2489.

[15] Klimenda F., Soukup J., Zmindak M.: Deformation of Aluminium Thin Plate, Manufacturing Technology, Vol. 16, No 1, 2016, pp. 124-129, ISSN 1213-2489. 